\title{
An analytical study of the nocturnal radiative cooling potential of typical photovoltaic/thermal module
}

\author{
Mingke Hu ${ }^{\text {a }}$, Bin Zhao ${ }^{\mathrm{b}}$, Xianze Ao ${ }^{\mathrm{b}}$, Suhendri ${ }^{\mathrm{a}}$, Jingyu Cao ${ }^{\mathrm{b}}$, Qiliang Wang ${ }^{\mathrm{c}}$, Saffa Riffat ${ }^{\mathrm{a}}$, \\ Yuehong $\mathrm{Su}^{\mathrm{a}, *}$, Gang Pei ${ }^{\mathrm{b}, *}$

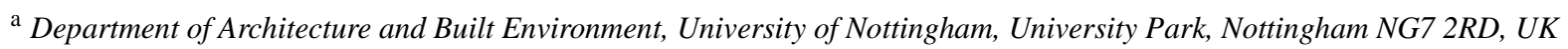 \\ ${ }^{\mathrm{b}}$ Department of Thermal Science and Energy Engineering, University of Science and Technology of China, Hefei 230027, China \\ ${ }^{c}$ Department of Building Services Engineering, The Hong Kong Polytechnic University, Kowloon, Hong Kong, China \\ *Corresponding author: yuehong.su@ nottingham.ac.uk; peigang @ustc.edu.cn
}

\begin{abstract}
Radiative cooling (RC) sees great developments in recent years due to its unique feature of sending waste heat to the cold universe without any additional energy consumption, which is extensively proved in many application scenarios, including its integration into solar installations. The comprehensive solar photovoltaic/thermal (PV/T) technology is becoming popular due to its multifunction and high overall efficiency. The integration of RC into a PV/T collector can further contribute to such merits by adding a night sky cooling function, so a PV/T-RC collector can produce electricity and heat during the daytime and provide cooling energy during the nighttime. Without any structural modification, a flat-plate PV/T collector with a typical glass cover is confirmed to be able to realize a good radiative cooling in the present study. A mathematic model for the nighttime performance evaluation of a typical PV/T module was developed to characterize the nocturnal cooling capacity of the module. Results suggest that the absorber plate can be cooled to nearly $9.5^{\circ} \mathrm{C}$ below the ambient air over a consecutive five hours nighttime period. Further parametric studies were carried out to
\end{abstract}


investigate the effect of some key structural and environmental parameters on the radiative cooling performance of the PV/T module. Under some favorable radiative cooling conditions, the absorber plate can realize a stagnation temperature of nearly $11^{\circ} \mathrm{C}$ lower than the ambient temperature and reach a maximum cooling power of over $50 \mathrm{~W} / \mathrm{m}^{2}$.

Keywords: solar energy; photovoltaic/thermal; PVT-RC; glass cover; radiative cooling; parametric study.

\section{Introduction}

Comparing to the widely applied vapor compression refrigerator, a radiative sky cooler shows advantages in terms of simplicity, sustainability, and environmental-friendliness [1]. Radiative sky cooling is a completely passive cooling strategy that takes the huge and cold sky as a natural heat sink $[2,3]$. Terrestrial objects radiatively throw heat to the sky through the well-known atmospheric window in $8-13 \mu \mathrm{m}$ and thus can reach a deep sub-ambient temperature if is carefully thermal-isolated and sunlight-rejected [4]. However, as the solar radiation projected onto the earth is generally one order greater than the radiative cooling power of earthbound bodies at room temperature, the sub-ambient cooling effect may be wiped out even a tiny portion of solar energy is absorbed [5]. Thanks to the advancements in micro- and nano-material technologies, it is engineering accessible to prepare radiative emitters that can achieve daytime radiative cooling under direct sunlight $[6,7]$. Nevertheless, radiative coolers are more likely to achieve high-performing cooling at nighttime with the absence of solar radiation. Nighttime radiative cooling can be very easily achieved using less demanding emitters [8]. 
Considering that solar installations are limited to run in the daytime, it would be appealing to extend its function for operation at night. By contrast, nighttime radiative coolers are generally unoperated during the daytime which seriously affects its own effectiveness. Therefore, developing a

\begin{tabular}{|llll}
\hline \multicolumn{2}{l}{ Nomenclature } & & \\
$c$ & specific heat capacity, $\mathrm{J} /(\mathrm{kg} \cdot \mathrm{K})$ & $\rho$ & density, $\mathrm{kg} / \mathrm{m}^{3}$ \\
$d$ & distance/thickness, $\mathrm{m}$ & $\sigma$ & Stefan-Boltzmann constant, $\mathrm{W} / \mathrm{m}^{2} \cdot \mathrm{K}^{4}$ \\
$E$ & radiant power, $\mathrm{W} / \mathrm{m}^{2}$ & $\lambda$ & wavelength, $\mu \mathrm{m}$ \\
$h$ & heat transfer coefficient, $\mathrm{W} /\left(\mathrm{m}^{2} \cdot \mathrm{K}\right)$ & $\varphi$ & inclination angle, $\mathrm{rad}$ \\
$k$ & thermal conductivity, $\mathrm{W} /(\mathrm{m} \cdot \mathrm{K})$ & $\theta$ & zenith angle, $\mathrm{rad}$ \\
$l$ & length, $\mathrm{m}$ & $\tau$ & transmittance, - \\
$N u$ & Nusselt number, - & $\mathrm{Abbreviation}$ and subscripts \\
$Q$ & Heat flux, $\mathrm{W} / \mathrm{m}^{2}$ & $\mathrm{a}$ & ambient air \\
$R a$ & Rayleigh number, - & $\mathrm{g}$ & glass cover \\
$t$ & calculation time step & $\mathrm{p}$ & absorber plate \\
$V$ & wind velocity, $\mathrm{m} / \mathrm{s}$ & rad & radiation \\
Greek & Symbols & $\mathrm{s}$ & sky \\
$\varepsilon$ & emissivity, - & &
\end{tabular}

new device that can work as a solar energy harvester during the daytime and as a radiative thermal emitter during the nighttime is meaningful and could remove the limitation of solar installations and radiative coolers regarding time availability. Fortunately, solar devices such as solar PV panels and solar thermal collectors are basically in flat-plate structure $[9,10]$, which is the same as the structure of most radiative coolers, making it possible to integrate them into one single module.

The superiorities of the combination of solar energy and radiative cooling (SE-RC) technologies such as multi-function, operation continuity, and seasonal adaptability has earned itself a spate of attention in the research community [11]. Researches on SE-RC can basically be categorized into three main areas: solar photovoltaic-radiative cooling (PV-RC) [12, 13], solar photothermal-radiative 
cooling (PT-RC) $[14,15]$, and solar photovoltaic/thermal-radiative cooling (PV/T-RC) [16, 17]. The first category focuses on developing a device that is capable of generating electricity by photovoltaic conversion during the daytime and providing coldness via radiative cooling at night. By adding the feature of radiative cooling, the PV module is also expected to operate at lower cell temperatures and thus gets a higher electrical efficiency [18]. The second category investigates the dual-functional collector which can offer heat through photothermal conversion and deliver radiative cooling energy respectively during the daytime and nighttime [19]. As heat and coldness are two completely opposite forms of energy, it is challenging to achieve high-performance solar heating and radiative cooling using the same surface. Resulting from the side effect introduced by radiative cooling, the solar thermal efficiency of a PT-RC collector with spectrally coupling surface is generally $15-20 \%$ lower than that of the typical solar thermal collector equipped with solar selective absorbing coatings [20]. However, recent advancements in optical switching surface [21] and spectrally filtered structure [22] offered strategies for pursuing both favorable cooling capacity and high solar thermal efficiency. As the solar photovoltaic/thermal (PV/T) collector combines the characteristic of solar photovoltaic and photothermal conversions together and shows the advantages of providing electricity and heat simultaneously [23], the third category involves further adding a radiative cooling function to the PV/T collector and making it a new combined cooling, heating and power (CHP) apparatus that delivers electricity and thermal energy during the daytime and offer cooling energy during the nighttime [24].

Regarding the PV/T-RC technology, current PV/T-RC collectors basically are developed from the typical flat-plate PV/T collectors, either by using the uncovered PV/T collector (see Figure 1.a) directly as a radiative cooler at night [25], or by replacing the glass cover of the covered PV/T collector (see Figure 1.b) with infrared transparent covers such as low-density polyethylene (PE) film [26] to achieve 
nocturnal radiative cooling as well (see Figure 1.c). The first approach exploits the high infrared emissivity of the encapsulated glass above the PV cells to radiate heat to the sky, but such a structure leads to a poor solar thermal efficiency and radiative cooling flux at big glass-ambient temperature differences due to the lack of a convection cover. The second approach takes enough account of the impact of heat convection between the collector and environment (an air gap is introduced), but the solar thermal efficiency of the PV/T-RC collector is still lower than that of the covered PV/T collector and the non-durability of the PE film is an unneglectable problem in real-world application.

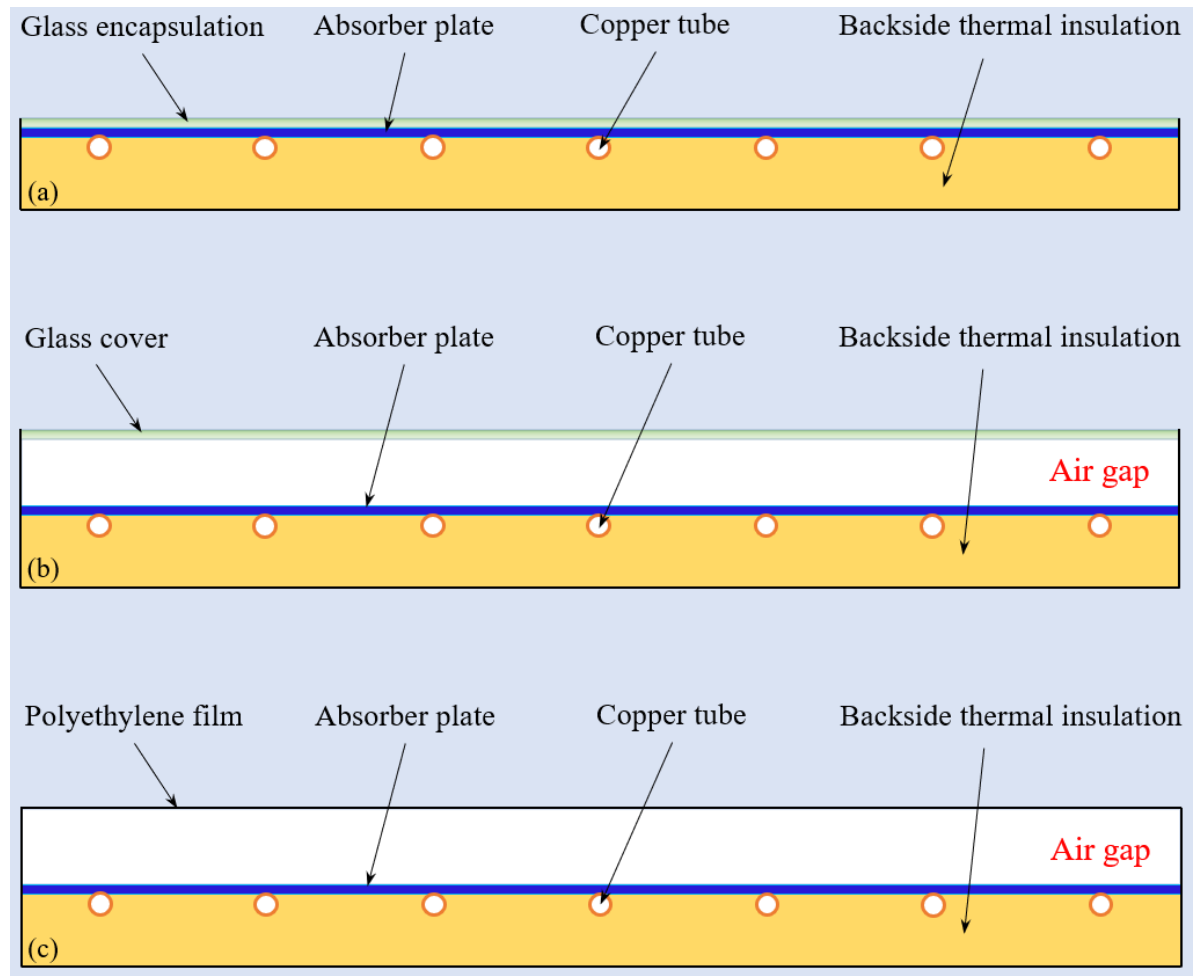

Fig. 1. The cross-section structure of three different flat-plate collectors. (a) Uncovered PV/T collector. (b) Covered

PV/T collector. (c) Covered PV/T-RC collector.

However, there is a possibility that has generally been ignored. That is, the covered flat-plate PV/T collector might have a profitable nocturnal radiative cooling capacity even without modifications to the convection cover. Unlike the plate of solar thermal collectors that show extremely low long-wave 
emissivity, the plate of the PV/T collector exhibits very high emissivity through the mid- and farinfrared bands and thus can emit strongly at room temperatures [27]. Though the glass cover prevents the direct heat exchange between the plate and the cold sky, the plate can firstly dissipate heat to the glass cover by heat radiation and convection, and then the glass cover dumps heat to the sky by radiative cooling. The glass cover acts as a thermal barrier between the plate (heat source) and the sky (heat sink), hence the heat flux between the two sources is reduced. However, thanks to the high longwave absorptivity and emissivity on both sides of the glass cover, the thermal resistance added by the glass cover would be expected to be at low-level and thus making the cooling flux still be considerable. Besides, if seeing the cooling capacity of a PV/T collector as an unexpected additional bonus, it is acceptable that the cooling performance of the covered PV/T collector is inferior to that of the modified PE film-based PV/T-RC collector. Moreover, as no structural modification is taken to the PV/T collector, its daytime electrical and thermal efficiencies will remain in high-standards and its durability is assured.

To the best of the authors' knowledge, no existing research focuses on investigating the nocturnal radiative cooling performance of the typical covered flat-plate $\mathrm{PV} / \mathrm{T}$ collector (with an air gap). Therefore, we presented a demonstration study on the nighttime cooling feasibility of a small-scale $\mathrm{PV} / \mathrm{T}$ collector in this study. By developing a mathematic model for the nighttime performance characterization of the PV/T module, we conducted a systematical assessment on the cooling performance of the module working in different working conditions and offer general guidance on improving its cooling capacity in the present study.

\section{Description of the PV/T module}


As shown in Fig. 2, The PV/T module, being arranged in small scale in this preliminary feasibility research, mainly includes a glass cover, an absorber plate, and a backside thermal insulation. The PV/T module, $0.4 \mathrm{~m}$ in length, $0.4 \mathrm{~m}$ in width, and $0.08 \mathrm{~m}$ in height, is placed horizontally to fully "see" the sky. The air gap height between the glass cover and plate is $0.03 \mathrm{~m}$, and the thickness of the backside thermal insulation is $0.05 \mathrm{~m}$. The spectral emissivity of the glass cover and plate in the spectrum of 2.5-25 $\mu \mathrm{m}$ were measured by a Fourier transform infrared spectrophotometer (Nicolet iS10) and are shown in Fig. 3. The detailed information of the PV/T module is listed in Table 1.

For a typical water-based PV/T collector as shown in Fig. 1(b), the water flowed from a circulating water tank will enter into the copper pipes which are connected to the backside of the absorber plate. During the nighttime radiative cooling working mode, the heat will be extracted from the water flow and transfer to the absorber through heat convection and conduction, and then be sent to the glass cover through heat convection and radiation before finally be dissipated to the sky via heat radiation. Cold water at the outlet of the PV/T module will be collected and flow back to the circulating water tank.

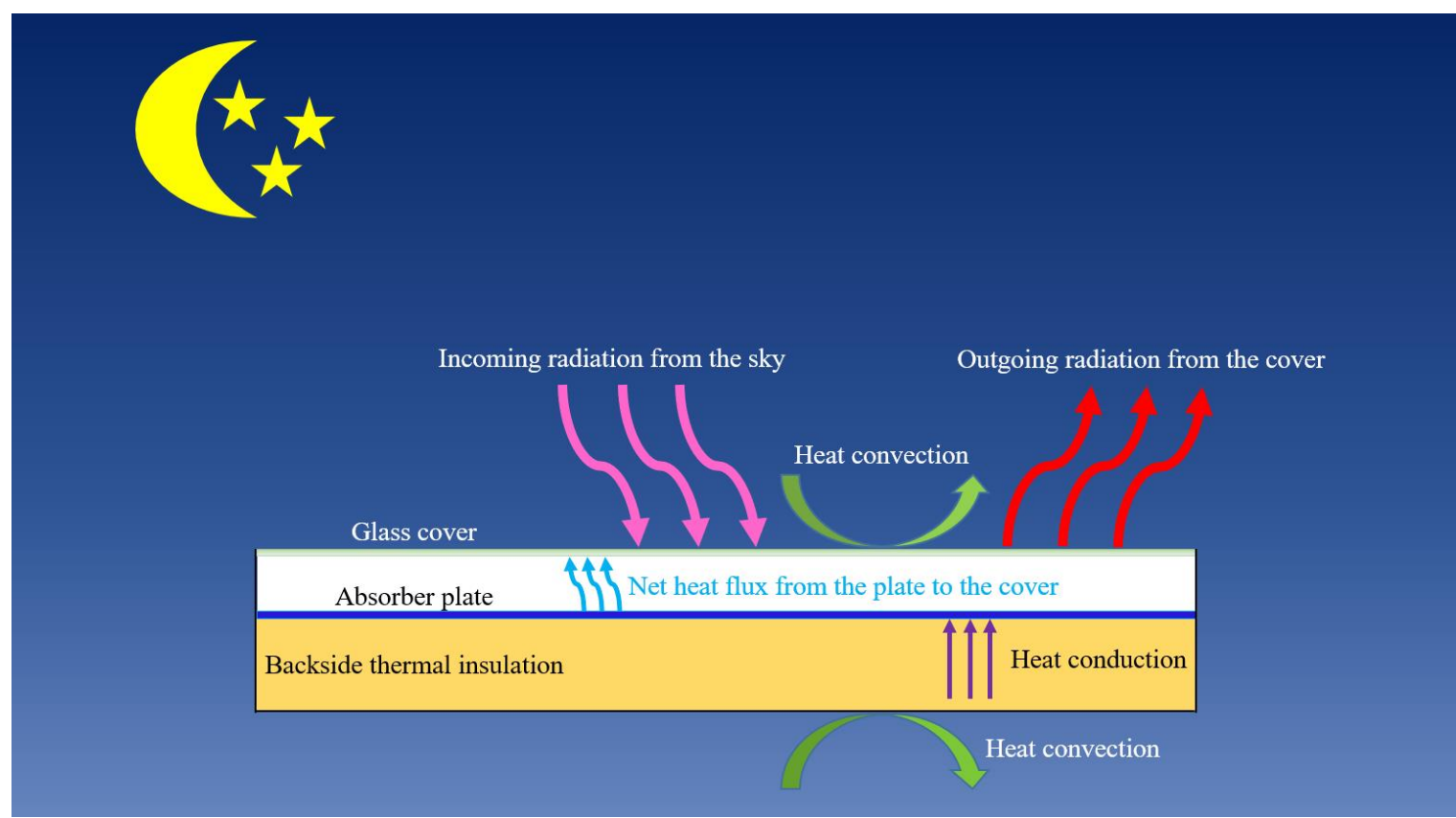


Fig. 2. The cross-section structure of the PV/T module and the primary heat exchange schematic in the nighttime.

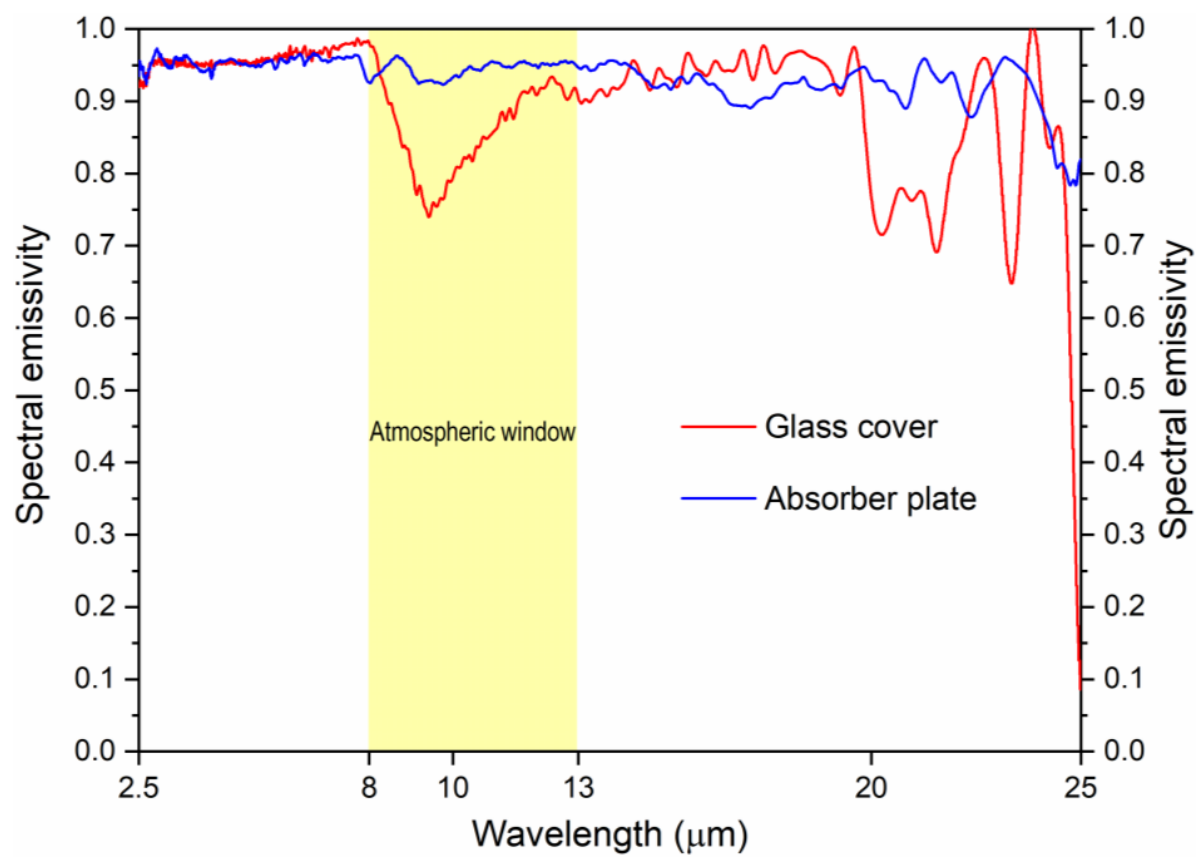

Fig. 3. The spectral emissivity of the glass cover and absorber plate of the PV/T module in the spectrum of 2.5-25

$\mu \mathrm{m}$.

Table 1. The detail information of the PV/T module

\begin{tabular}{lll}
\hline Component & Parameter & Value \\
\hline Glass cover & Area $(\mathrm{L} \times \mathrm{W})$ & $0.4 \times 0.4 \mathrm{~m}$ \\
& Thickness & $0.0028 \mathrm{~m}$ \\
& Emissivity $(0.3-2.5 \mu \mathrm{m})$ & 0.89 \\
Absorber plate & Thickness & $0.0023 \mathrm{~m}$ \\
& Emissivity $(0.3-2.5 \mu \mathrm{m})$ & 0.95 \\
Backside thermal insulation & Thickness & $0.05 \mathrm{~m}$ \\
& Thermal conductivity & $0.033 \mathrm{~W} /(\mathrm{m} \cdot \mathrm{K})$ \\
Air gap & Height & $0.03 \mathrm{~m}$ \\
\hline
\end{tabular}

\section{Theoretical model}

To assess the cooling performance of the PV/T module working in the nighttime, a theoretical model is developed based on energy-balance theory. During the modeling and simulation, the following simplifications are applied [28]:

- The spectral emissivity of the glass cover and plate are not temperature- and angle-dependent 


\subsection{Energy-balance equation of the glass cover}

The energy-balance equation of the glass cover is expressed as:

$$
h_{\mathrm{ag}}\left(T_{\mathrm{a}}-T_{\mathrm{g}}\right)+h_{\mathrm{gp}}\left(T_{\mathrm{p}}-T_{\mathrm{g}}\right)+Q_{\mathrm{s}_{\text {rad }}}-Q_{\mathrm{g} \_ \text {_rad }}=\left\{\begin{array}{l}
\rho_{\mathrm{g}} \mathrm{c}_{\mathrm{g}} d_{\mathrm{g}} \frac{\partial T_{\mathrm{g}}}{\partial t}, \quad \text { dynamic state } \\
0, \quad \text { steady state }
\end{array}\right.
$$

where $h_{\mathrm{ag}}$ is the convective heat transfer coefficient between the ambient air and glass cover, $\mathrm{W} /\left(\mathrm{m}^{2} \cdot \mathrm{K}\right)$; $T_{\mathrm{a}}, T_{\mathrm{g}}$, and $T_{\mathrm{p}}$ are the temperatures of the ambient air, glass cover, and absorber plate, respectively, $\mathrm{K}$; $h_{\mathrm{gp}}$ is the overall convective and radiative heat transfer coefficient between the glass cover and plate, $\mathrm{W} /\left(\mathrm{m}^{2} \cdot \mathrm{K}\right)$; and $Q_{\text {S__ad }}$ and $Q_{\mathrm{g} \_ \text {rad }}$ denotes the thermal emission absorbed by the glass cover from the sky and the outgoing thermal emission of the glass cover, respectively, $\mathrm{W} / \mathrm{m}^{2} ; \rho_{\mathrm{g}}$ and $c_{\mathrm{g}}$ and $d_{\mathrm{g}}$ respectively refer to the density, specific heat capacity, and thickness of the glass cover, $\mathrm{kg} / \mathrm{m}^{3}$ and $\mathrm{J} /(\mathrm{kg} \cdot \mathrm{K}), \mathrm{m} ; t$ is the time step, s.

The convective heat transfer coefficient between the glass cover and ambient is derived as [32]:

$$
h_{\mathrm{ag}}=2.8+3.0 \mathrm{~V}_{\mathrm{a}}
$$

where $V_{\mathrm{a}}$ is the ambient wind velocity, $\mathrm{m} / \mathrm{s}$.

The overall convective radiative heat transfer coefficient between the glass cover and plate is calculated as: 


$$
h_{\mathrm{gp}}=h_{\mathrm{c} \_ \text {_op }}+h_{\mathrm{gp} \_ \text {rad }}=N u \frac{k_{\mathrm{a}}}{d_{\mathrm{gp}}}+\frac{\sigma\left(T_{\mathrm{g}}^{2}+T_{\mathrm{p}}^{2}\right)\left(T_{\mathrm{g}}+T_{\mathrm{p}}\right)}{1 / \varepsilon_{\mathrm{g}}-1 / \varepsilon_{\mathrm{p}}-1}
$$

where $h_{\mathrm{c}_{-} \text {top }}$ and $h_{\mathrm{gp} \_ \text {rad }}$ are respectively the convective and radiative heat transfer coefficient between the glass cover and plate, $\mathrm{W} /\left(\mathrm{m}^{2} \cdot \mathrm{K}\right) ; N u$ is the Nusselt number; $k_{\mathrm{a}}$ is the thermal conductivity of air in the air gap, $\mathrm{W} /(\mathrm{m} \cdot \mathrm{K}) ; d_{\mathrm{gp}}$ is the air gap height, $\mathrm{m}$; $\sigma$ is the Stefan-Boltzmann constant, $5.67 \times 10^{-8}$ $\mathrm{W} /\left(\mathrm{m}^{2} \cdot \mathrm{K}^{4}\right)$; and $\varepsilon_{\mathrm{g}}$ and $\varepsilon_{\mathrm{p}}$ are respectively the total, hemispherical emissivity of the glass cover and plate.

The Nusselt number for a rectangular enclosure can be calculated as [33]:

$$
N u=\left\{\begin{array}{l}
1+1.44\left(1-\frac{1708 \cdot(\sin 1.8 \varphi)^{1.6}}{R a \cdot \cos \varphi}\right)\left[1-\frac{1708}{R a \cdot \cos \varphi}\right]^{+}+\left[\left(\frac{R a \cdot \cos \varphi}{5830}\right)^{1 / 3}-1\right]^{+}, \quad \text { if } T_{\mathrm{g}}<T_{\mathrm{p}} \\
1+\left[0.364 \frac{l_{\mathrm{p}}}{d_{\mathrm{gp}}} R a^{1 / 4}-1\right] \sin \varphi, \quad \text { if } T_{\mathrm{g}}>T_{\mathrm{p}} \\
0, \quad \text { if } T_{\mathrm{g}}=T_{\mathrm{p}}
\end{array}\right.
$$

where the + exponent indicates that only positive values are used for terms within the square brackets; in case of negative values, zero is used; $\varphi$ is the inclination angle of the collector, rad; and $R a$ is the Rayleigh number.

The thermal emission absorbed by the glass cover from the sky is written as [34]:

$$
Q_{\mathrm{s} \text { rad }}=2 \int_{0}^{\infty} \int_{0}^{\pi / 2} \varepsilon_{\mathrm{s}, \lambda}(\lambda, \theta) E_{\mathrm{b}, \lambda}\left(\lambda, T_{\mathrm{a}}\right) \alpha_{\mathrm{g}, \lambda}(\lambda, \theta) \sin \theta \cos \theta \mathrm{d} \theta \mathrm{d} \lambda
$$

and the outgoing thermal emission of the glass cover is calculated as [34]:

$$
Q_{\mathrm{g} \_ \text {rad }}=2 \int_{0}^{\infty} \int_{0}^{\pi / 2} E_{\mathrm{b}, \lambda}\left(\lambda, T_{\mathrm{g}}\right) \varepsilon_{\mathrm{g}, \lambda}(\lambda, \theta) \sin \theta \cos \theta \mathrm{d} \theta \mathrm{d} \lambda
$$

where $\varepsilon_{\mathrm{s}, \lambda}(\lambda, \theta)$ denotes the spectral, directional emissivity of the atmosphere; $\lambda$ is the wavelength, $\mu \mathrm{m}$; $\theta$ is the zenith angle, rad; $E_{\mathrm{b}, \lambda}$ is the spectral radiant power of the blackbody, $\mathrm{W} /\left(\mathrm{m}^{2} \cdot \mu \mathrm{m}\right) ;$ and $\alpha_{\mathrm{g}, \lambda}(\lambda, \theta)$ refers to the spectral, directional absorptivity of the glass cover. $\varepsilon_{\mathrm{s}, \lambda}(\lambda, \theta)$ is computed as [6]: 
where $\tau_{\mathrm{s}, \lambda}(\lambda, \theta)$ is the transmittance of the atmosphere in the zenith direction.

\subsection{Energy-balance equation of the absorber plate}

The energy-balance equation of the absorber plate as:

$$
h_{\mathrm{c} \_ \text {bottom }}\left(T_{\mathrm{a}}-T_{\mathrm{p}}\right)+h_{\mathrm{gp}}\left(T_{\mathrm{g}}-T_{\mathrm{p}}\right)=\left\{\begin{array}{l}
\rho_{\mathrm{p}} \mathrm{c}_{\mathrm{p}} d_{\mathrm{p}} \frac{\partial T_{\mathrm{p}}}{\partial t}, \text { dynamic state } \\
0, \quad \text { steady state }
\end{array}\right.
$$

where $\rho_{\mathrm{p}}$ and $c_{\mathrm{p}}$ and $d_{\mathrm{p}}$ correspondingly signify the density, specific heat capacity, and thickness of the plate, $\mathrm{kg} / \mathrm{m}^{3}$ and $\mathrm{J} /(\mathrm{kg} \cdot \mathrm{K}), \mathrm{m} ; h_{\mathrm{c} \_ \text {bottom }}$ is the overall conductive-convective heat transfer coefficient between the ambient and the backside of the plate, $\mathrm{W} /\left(\mathrm{m}^{2} \cdot \mathrm{K}\right)$, and is computed as [35]:

$$
h_{\mathrm{c} \text { bottom }}=\frac{1}{1 / h_{\mathrm{ag}}+d_{\mathrm{b}} / k_{\mathrm{b}}}
$$

where $h_{\mathrm{ab}}$ equals $h_{\mathrm{ag}}$ in expression, $d_{\mathrm{b}}$ and $k_{\mathrm{b}}$ are correspondingly the thickness and thermal conductivity of the backside thermal insulation, $\mathrm{m}$ and $\mathrm{W} /(\mathrm{m} \cdot \mathrm{K})$.

A computer program using MATLAB software was developed based on the above theoretical model to predict the nocturnal cooling performance of the PV/T module.

\section{Results and discussion}

\subsection{Model validation}

The model developed in Section 3 is firstly validated by experimental data before use to characterize the performance of the PV/T module. The author did not fabricate and test a same-size PV/T module but conducted an experimental study on a structurally highly similar solar photothermal (PT) module on 1st April 2019 in Hefei, China [36]. The two modules both include a glass cover, an absorber plate, an air gap, and a backside thermal insulation. Properties of the glass cover and backside 
thermal insulation are the same for the two modules. The main difference between the two modules is the property of the absorber plate. The absorber plate of the PT module is an aluminum plate coated by a solar selective absorbing coating which shows extremely low infrared emissivity (about 0.05 ), while that of the PV/T module is an aluminum plate covered by a PV layer which presents extremely high infrared emissivity (about 0.95). However, this difference will only cause the difference in heat transfer capacity but not mechanism among the plate and other parts around it (e.g., glass cover, air in the air gap, backside thermal insulation). Therefore, the mathematic model developed for the PV/T module in the present study can also be employed to characterize the cooling performance of the PT module. To characterize the difference between experimental and simulation results, the root-meansquare deviation (RMSD) method is employed [33]:

$$
R M S D=\sqrt{\frac{\sum\left[\left(X_{\mathrm{sim}, i}-X_{\text {exp }, i}\right) / X_{\text {exp }, i}\right]^{2}}{n}}
$$

where $X_{\mathrm{sim}, i}$ and $X_{\exp , i}$ are respectively the simulated and experimental values; $n$ denotes the number of measurements.

During the experiments, four thermocouples with a measuring inaccuracy of $\pm 0.5^{\circ} \mathrm{C}$, were placed on the central point of the upper surface of the glass cover and absorber plate, as well as the lower surface of the glass cover and absorber plate, respectively. The average temperature of the upper and lower surfaces was recorded as the temperature of the glass cover and absorber plate, correspondingly. Another thermocouple with the same inaccuracy was arranged in a thermometer shelter for the measurement of the ambient temperature. As illustrated in Fig. 4, a favorable consistency was observed between the experimental and simulated results temperatures of both the glass cover and absorber plate of the PT module. In specific, the stagnation temperature deviation between the experimental and predicted average values is only $0.10 \pm 0.5{ }^{\circ} \mathrm{C}$ for the cover and $0.53 \pm 0.5{ }^{\circ} \mathrm{C}$ for the plate. Moreover, 
the $R M S D$ of the stagnation temperature (in Kelvin scale) of the cover and plate is only $0.10 \%$ and $0.19 \%$, respectively. Hence, the mathematic model is accurate enough in characterizing the nighttime cooling performance of the PV/T module in this study.

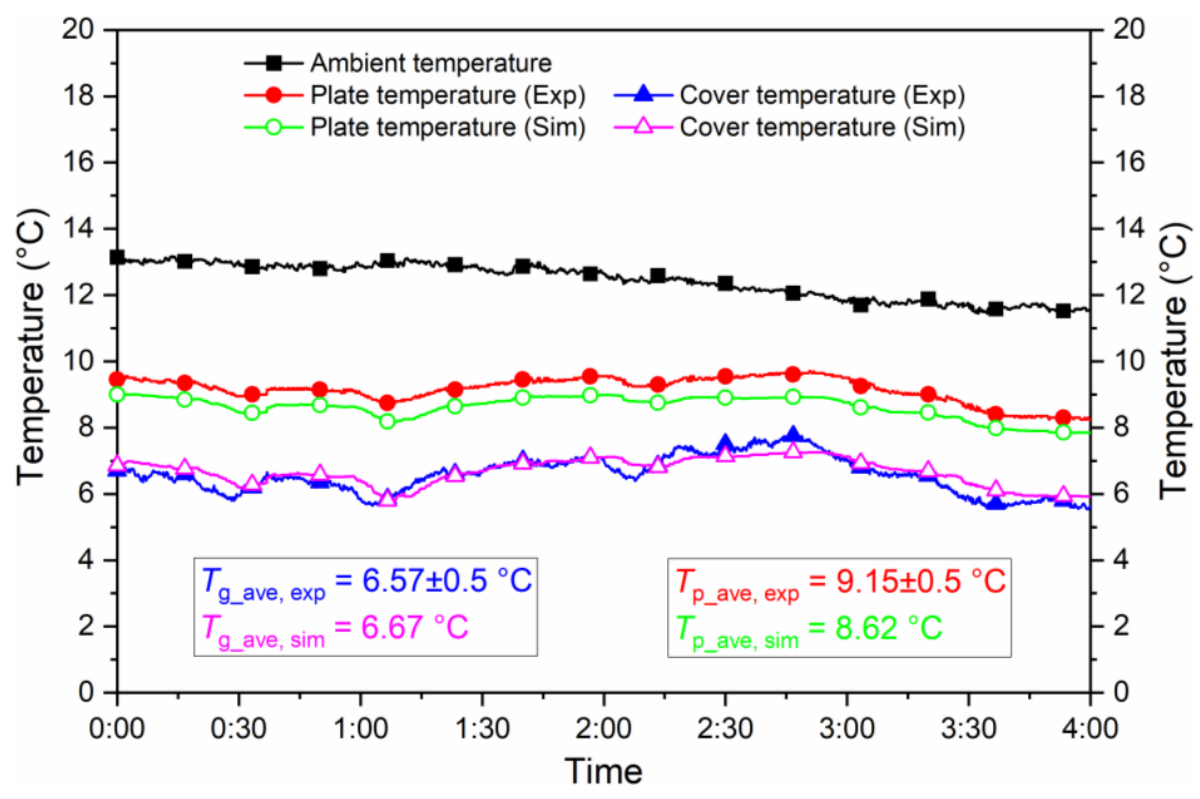

Fig. 4. Experimental and simulated temperatures of the glass cover and absorber plate of a solar photothermal module on $1^{\text {st }}$ April 2019 in Hefei, China.

\subsection{Stagnation temperature fluctuation through a consecutive five hours}

Stagnation temperature, also named as equilibrium temperature, is the lowest possible temperature a radiative emitter can reach by itself. The cooling power falls to zero when the emitter reaches its stagnation temperature. Based on the validated mathematic model, the nighttime radiative cooling performance of the PV/T module is investigated. Firstly, we characterized the sub-ambient temperature profiles of the glass cover and plate through a consecutive five hours on 1st September, 2019 in Hefei, China. The dynamic state model in Eqs. (1) and (8) are applied in this case. As shown in Fig. 5, the ambient air temperature remains relatively stable at around $25.7^{\circ} \mathrm{C}$ while the wind velocity fluctuates significantly with an average value of about $1.2 \mathrm{~m} / \mathrm{s}$. The temperatures of both the glass cover and plate both decrease by several degrees below the ambient temperature, indicating that radiative sky 
cooling indeed has a well-marked influence on the temperature change of the PV/T module at night. The stagnation temperature of the glass cover and plate is rather close over the simulated operation period. The glass cover is the thermal emitter of the PV/T module and its temperature reduces averagely by $7.29{ }^{\circ} \mathrm{C}$ through dissipating heat to the sky. The plate sends heat to the sky indirectly through radiating heat to the glass cover, and its stagnation temperature is $6.61{ }^{\circ} \mathrm{C}$ lower than the ambient temperature on average, with a maximum value of $9.42{ }^{\circ} \mathrm{C}$. It is admitted that, due to the extremely low long-wave transmittance of the glass cover, the plate cannot "see" the cold sky in midand far-infrared wavelengths and thus its radiative cooling capacity is suppressed heavily compared to typical radiative cooling modules in which a long-wave transparent cover is employed. For example, when a low-density PE film is used as a long-wave transparent cover, the average stagnation temperature of the plate is lower than the ambient temperature by $13.21{ }^{\circ} \mathrm{C}$, compared to $6.61{ }^{\circ} \mathrm{C}$ obtained with a glass cover. However, our results prove that, without any structural modification, a typical PV/T module exhibit an additional cooling potential during the nighttime which can be exploited in real-world application.

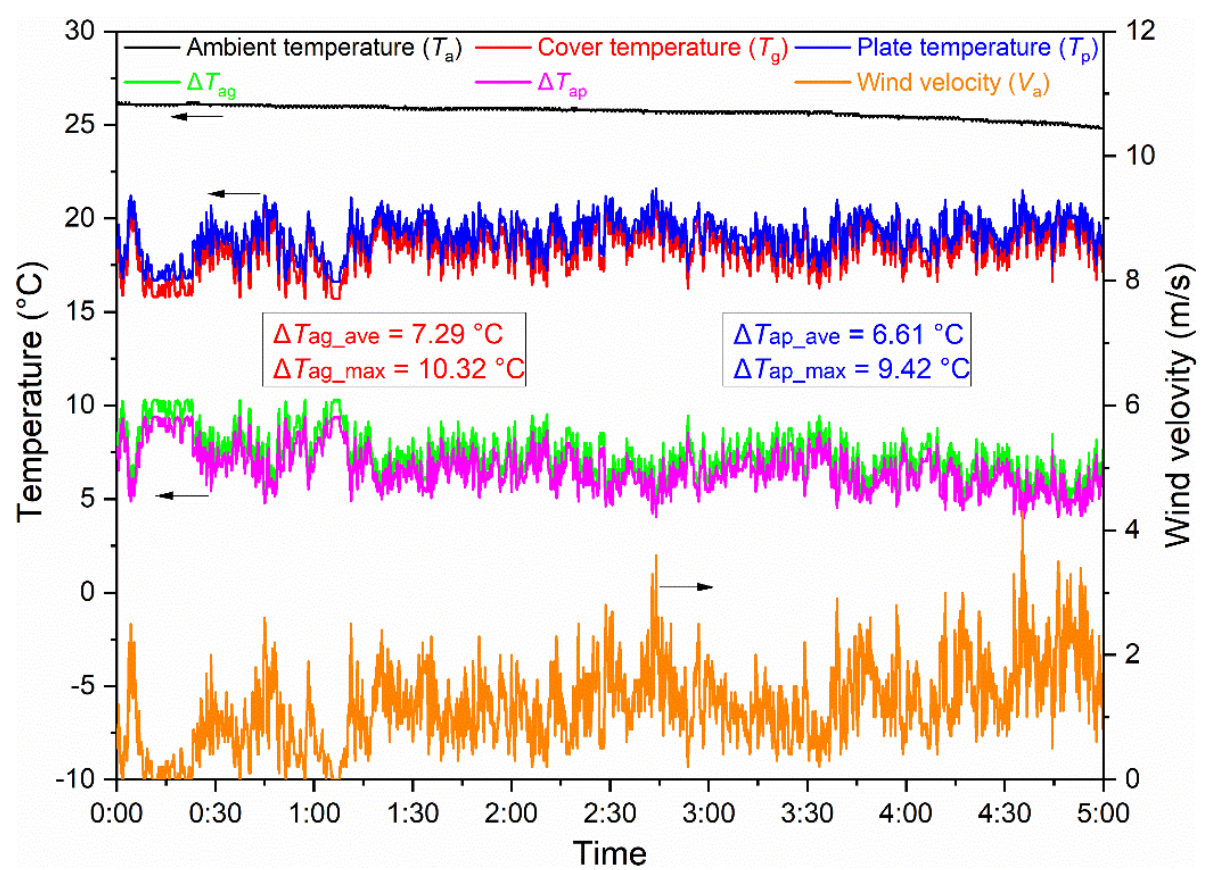


Fig. 5. The temperature of the glass cover and plate, and ambient conditions on $1^{\text {st }}$ September, 2019 in Hefei,

China.

\subsection{Parametric study}

The radiative cooling performance of the PV/T module is influenced by many internal and external parameters such as plate emissivity, cover emissivity, sky transmittance, wind velocity, ambient temperature, etc. In this section, we conducted a parametric study to clarify the impact mechanism of some key factors on the radiative cooling behavior of the PV/T module and direct ways to improve its cooling capacity. The steady state model in Eqs. (1) and (8) is applied in this section.

\subsubsection{Plate emissivity}

Determined by the component materials and dimensions, the plate shows an emissivity as high as 0.95. To evaluate the effect of plate emissivity on the radiative cooling performance of the PV/T module, we arranged another three typical plates with different long-wave emissivity profiles, namely, a photothermal (PT) plate coated with solar selective absorbing coatings, two reference PV/T plates with a spectral emissivity of 0.5 and 1 , respectively (see Fig. 6). The ambient temperature and wind velocity are chosen as $30{ }^{\circ} \mathrm{C}$ and $1 \mathrm{~m} / \mathrm{s}$, respectively. The atmospheric transmittance profile is adopted from the MODTRAN website [37]. As shown in Fig. 7, higher plate emissivity stands for higher cooling power. Owing to its unity-emissivity through the calculated bands, the reference plate 2 shows the best cooling capacity among the four plates, with a cooling power of $36.55 \mathrm{~W} / \mathrm{m}^{2}$ when the plate temperature equals the ambient temperature. The cooling performance of the PV/T module ranks second, with the maximum cooling power and stagnation temperature of the plate being $35.87 \mathrm{~W} / \mathrm{m}^{2}$ and $22.94{ }^{\circ} \mathrm{C}$, respectively. As the cooling power of the PV/T module is very close to that of the reference plate 2 , there is little space and meaning to improve the cooling performance by developing 
a plate with greater emissivity than the current one. With an emissivity of 0.5 , the reference plate 1 exhibit a moderate cooling capacity among the four plates. By contrast, the PT plate shows a much lower maximum cooling power $\left(17.49 \mathrm{~W} / \mathrm{m}^{2}\right)$ than that of the other three plates, indicating that its cooling performance is very poor due to the very limited long-wave emissivity. The stagnation temperature of the four plates, on the other hand, are rather close, with the temperature difference being less than $1.1{ }^{\circ} \mathrm{C}$. Therefore, compared to the PT plate, the PV/T plate is much sensitive to the plate temperature in terms of the cooling flux.

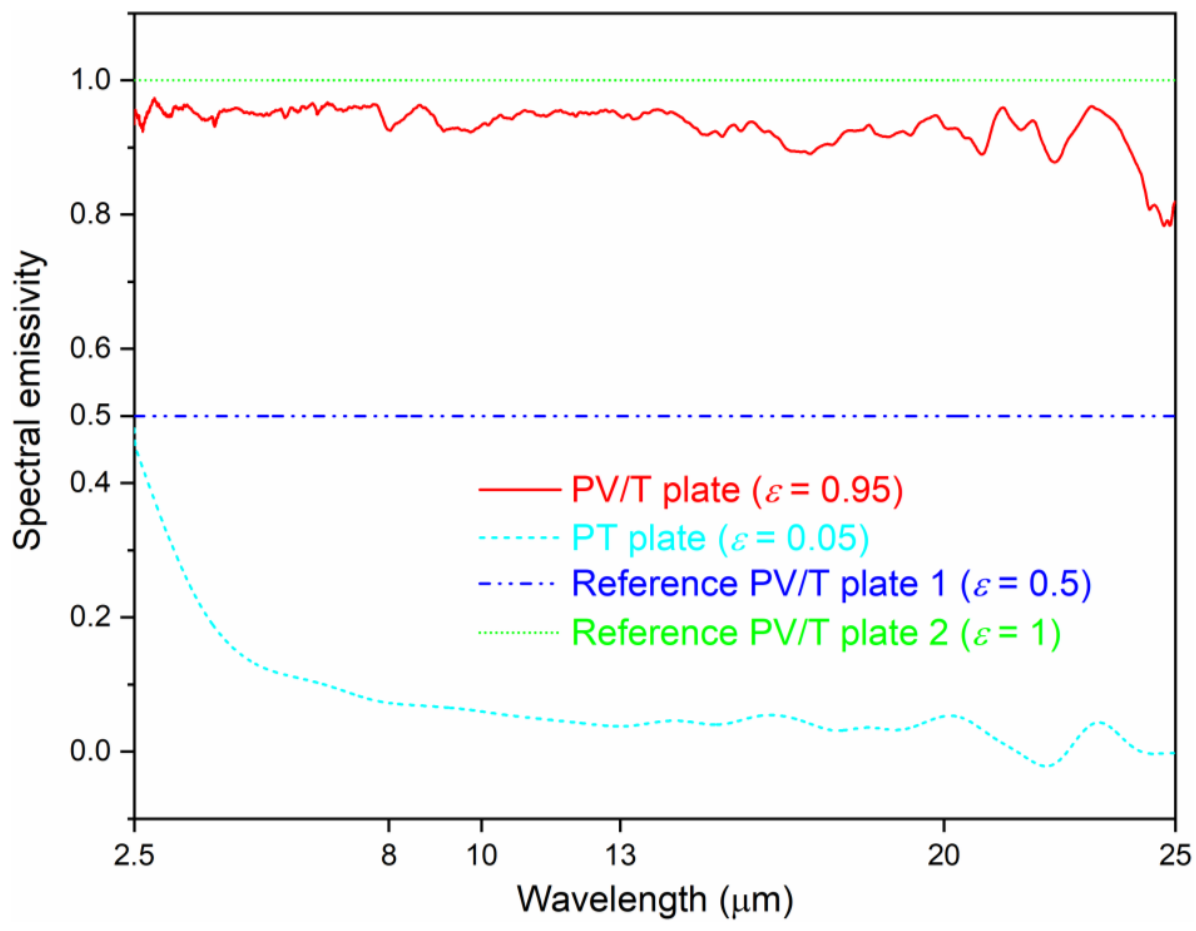

Fig. 6. The spectral emissivity of four typical plates. 


\subsubsection{Cover emissivity}

As the cover is the only radiative sky cooling unit of the present PV/T module, its long-wave emissivity characteristic will greatly affect the nighttime cooling performance of the module. Fortunately, the glass cover has already possessed relatively high mid- and far-infrared emissivity and thus can contribute to the temperature reduction of the plate. However, the current PV/T module may still have the potential of improving cooling performance by elevating the emissivity of the glass cover, especially in the atmospheric window band. As silica, the main component of the glass cover, shows a strong impedance mismatch with air near $10 \mu \mathrm{m}$ because of its strong phonon-polariton resonances, a big emissivity dip near this wavelength is formed. This dip may cause a large thermal emissionreduction of the glass cover as its emissive power coincidently peaks around $10 \mu \mathrm{m}$ according to the Wien's displacement law. In this study, we designed four types of covers (see Fig. 8) to demonstrate the effect of cove emissivity on the cooling performance of the PV/T module. In particular, to illustrate 
the cooling performance deterioration caused by the emissivity dip near $10 \mu \mathrm{m}$, we proposed a modified cover with a spectral emissivity of 0.95 within the original dip. Besides, another two ideal covers were proposed as references, the ideal cover 1 shows unity-emissivity and the ideal cover 2 has zero-emissivity but unity-transmittance.

It is important to note that Eqs. (1) and (8) are changed to the following two equations when the ideal cover 2 is employed:

$$
\begin{aligned}
& h_{\mathrm{ag}}\left(T_{\mathrm{a}}-T_{\mathrm{g}}\right)+h_{\mathrm{gp}}\left(T_{\mathrm{p}}-T_{\mathrm{g}}\right)=0 \\
& h_{\mathrm{c} \_ \text {bottom }}\left(T_{\mathrm{a}}-T_{\mathrm{p}}\right)+h_{\mathrm{gp}}\left(T_{\mathrm{g}}-T_{\mathrm{p}}\right)+Q_{\mathrm{s} \_ \text {rad }}-Q_{\mathrm{p} \_ \text {rad }}=0
\end{aligned}
$$

Additionally, the thermal emission absorbed by the plate from the sky and the outgoing thermal emission of the plate are respectively expressed as:

$$
Q_{\mathrm{s} \_\mathrm{rad}}=2 \int_{0}^{\infty} \int_{0}^{\pi / 2} \varepsilon_{\mathrm{s}, \lambda}(\lambda, \theta) E_{\mathrm{b}, \lambda}\left(\lambda, T_{\mathrm{a}}\right) \alpha_{\mathrm{p}, \lambda}(\lambda, \theta) \sin \theta \cos \theta \mathrm{d} \theta \mathrm{d} \lambda
$$

and

$$
Q_{\mathrm{p} \_ \text {rad }}=2 \int_{0}^{\infty} \int_{0}^{\pi / 2} E_{\mathrm{b}, \lambda}\left(\lambda, T_{\mathrm{g}}\right) \varepsilon_{\mathrm{p}, \lambda}(\lambda, \theta) \sin \theta \cos \theta \mathrm{d} \theta \mathrm{d} \lambda
$$

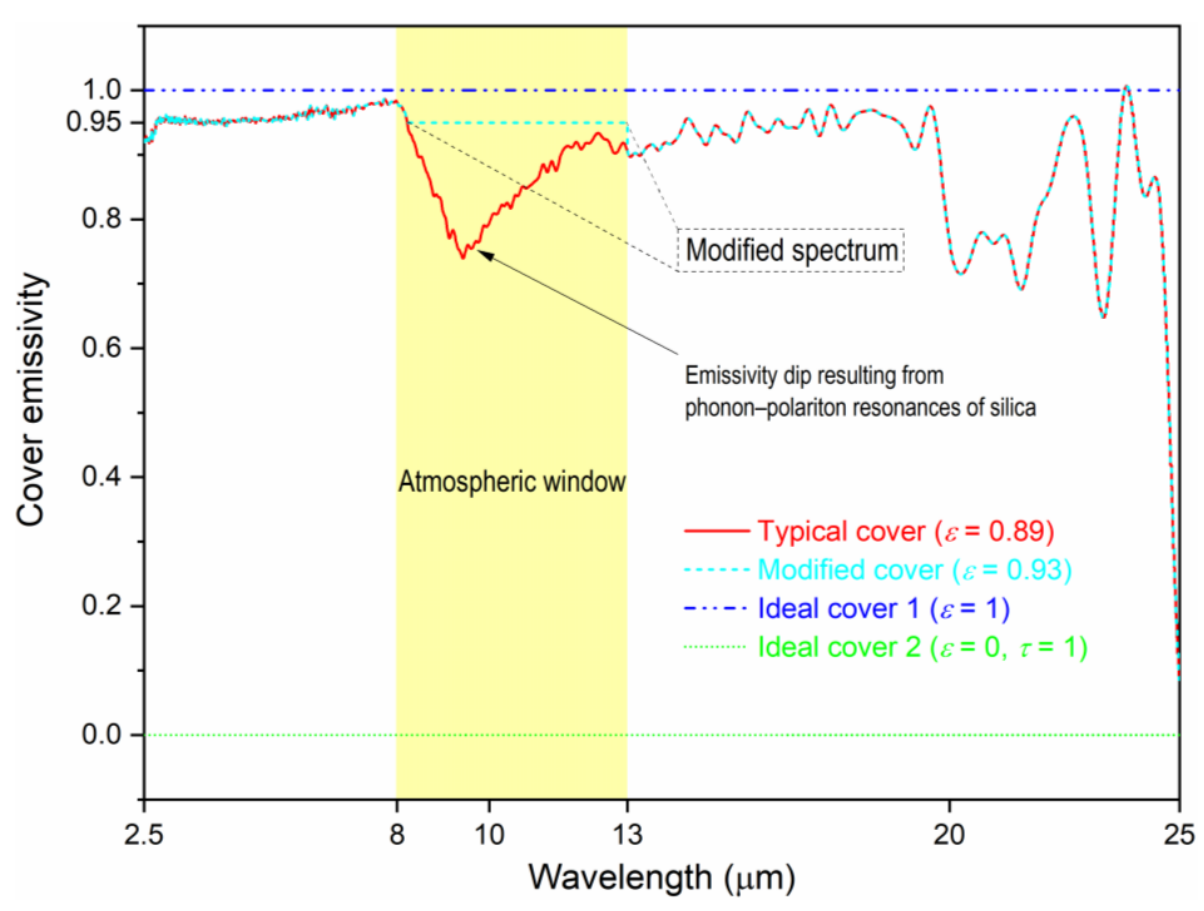

Fig. 8. The spectral emissivity of four typical covers of the PV/T module. 
As shown in Fig. 9, the modified cover helps increase the maximum cooling power of the PV/T module by $10.2 \%$ from 35.87 to $39.53 \mathrm{~W} / \mathrm{m}^{2}$, indicating that removing the emissivity dip near $10 \mu \mathrm{m}$ is of significance to enhance the cooling performance of the PV/T module. The ideal cover 1 corresponds to higher maximum cooling power, but the improvement compared to the modified cover is indistinctive. Considering that the ideal cover 1 is engineering inaccessible, this improvement will be even smaller for a near-ideal cover and thus further optimization on the spectral emissivity of the modified cover is not worth pursuing. In contrast, the PV/T module equipped with the ideal cover 2 shows a much better cooling performance than the rest three PV/T modules. Its maximum cooling power and stagnation temperature reach $96.65 \mathrm{~W} / \mathrm{m}^{2}$ and $14.97{ }^{\circ} \mathrm{C}$, respectively. As the ideal cover 2 is totally transparent through the calculated spectrum, the plate can freely exchange radiative heat with the cold sky where the temperature is much lower than the glass cover, hence the plate can be cooled down to a lower stagnation temperature or get a higher maximum cooling power.

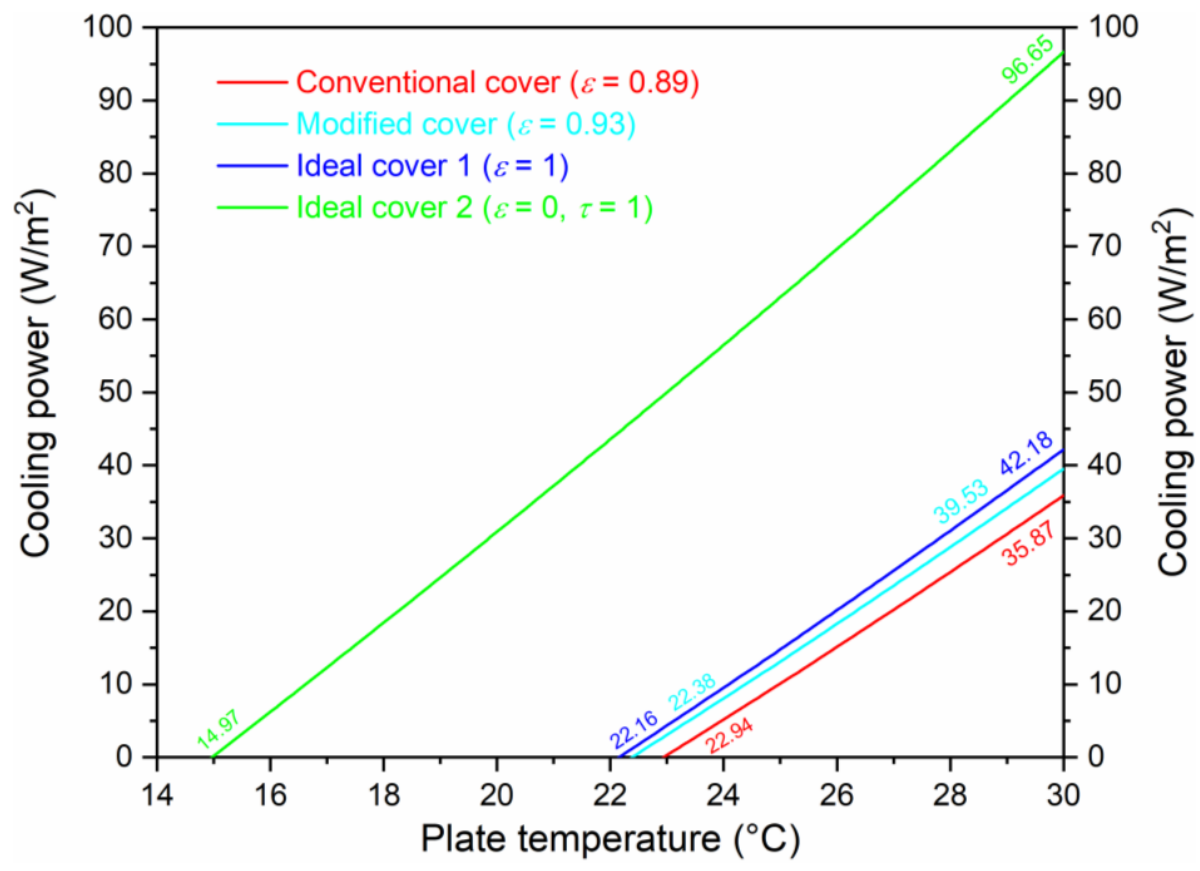

Fig. 9. The cooling power of four modules with different typical plate emissivity. The ambient temperature and wind velocity are set at $30{ }^{\circ} \mathrm{C}$ and $1 \mathrm{~m} / \mathrm{s}$, respectively. 


\subsubsection{Atmospheric transmittance}

We can treat the atmosphere as a radiative thermal barrier between the radiative cooler and sky as the upward thermal emission from terrestrial objects should pass through the atmosphere before dissipates into the cold sky. Therefore, the transmission property of the atmosphere is a key factor to determine the radiative cooling performance of the PV/T module. Generally, drier climate results in higher atmospheric transmittance. Fig. 10 illustrates three different atmospheric transmittance profiles corresponding to three different total water vapor columns (TWC). The TWC mainly affects the atmospheric transmittance in the $8-13 \mu \mathrm{m}$ atmospheric window and the secondary atmospheric window lies around $18 \mu \mathrm{m}$.

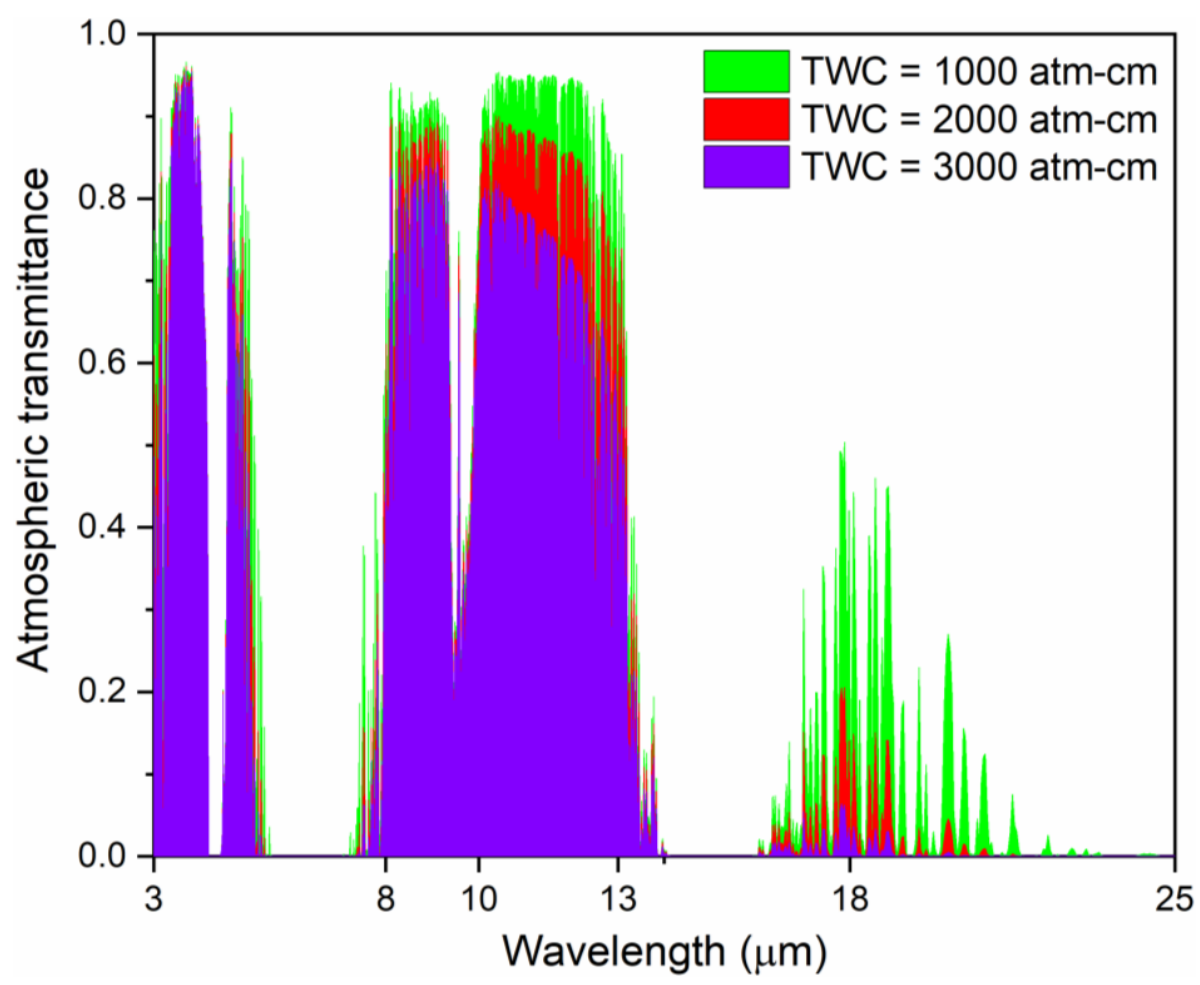

Fig. 10. The transmission properties of the atmosphere under different total water vapor columns.

As the results shown in Fig. 11, lower TWC leads to higher maximum cooling power and lower stagnation temperature of the plate. Specifically, as the TWC decreases from 3000 to $1000 \mathrm{~atm}-\mathrm{cm}$, the maximum cooling flux of the plate increases dramatically by $54.5 \%$ from 27.18 to $42.33 \mathrm{~W} / \mathrm{m}^{2}$, 
and the stagnation temperature of the plate declines from 24.61 to $21.68{ }^{\circ} \mathrm{C}$. Therefore, the cooling performance of the PV/T module will benefit from dry atmospheric conditions and is more suitable to be applied in arid geographic regions if cooling energy is preferred.

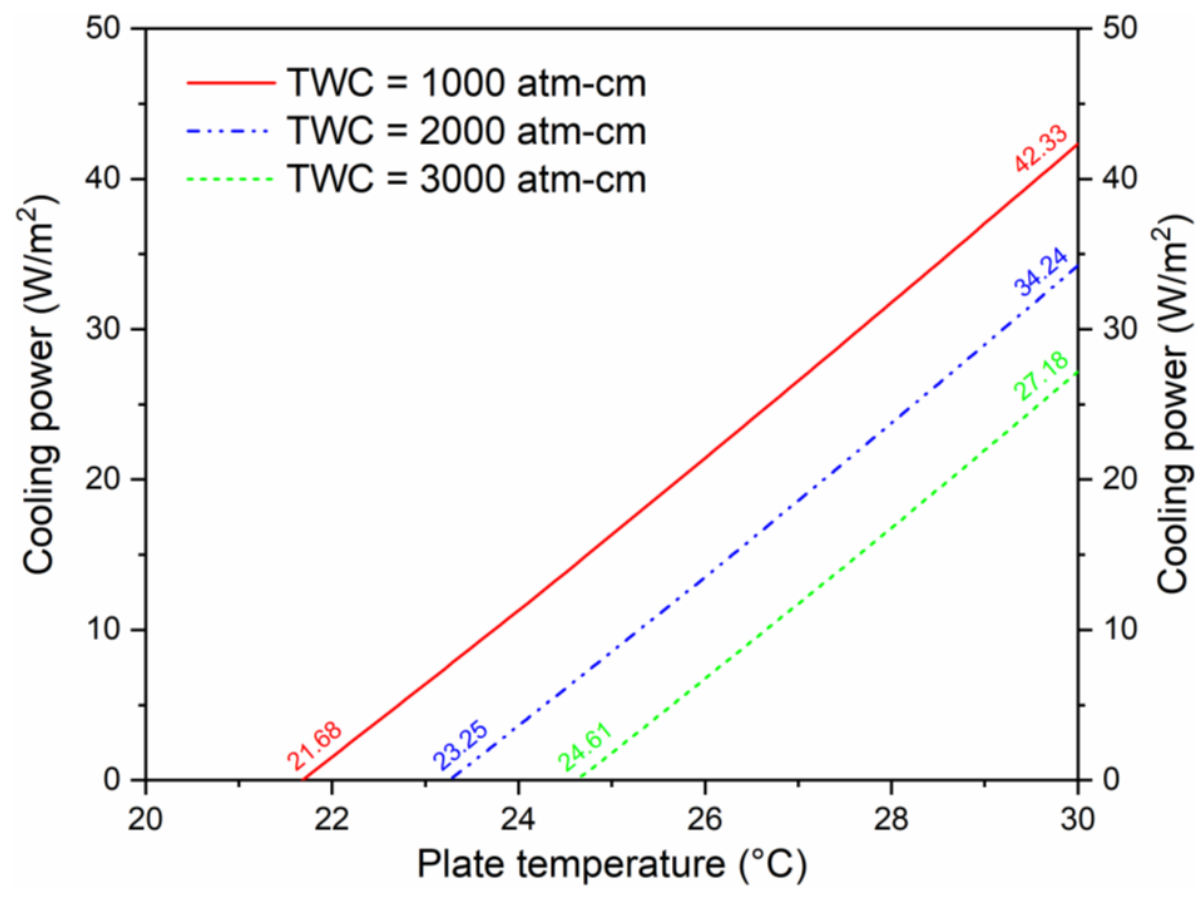

Fig. 11. The cooling power of the plate under different total water vapor columns. The ambient temperature and wind velocity are set at $30^{\circ} \mathrm{C}$ and $1 \mathrm{~m} / \mathrm{s}$, respectively.

\subsubsection{Non-radiative heat coefficient}

Except transfer heat to the glass cover via heat radiation, the plate also exchanges heat with the glass cover by heat convection (related to " $h_{\mathrm{c}_{-} \text {top" }}$ " in Eq. (3)) and with the backside environment

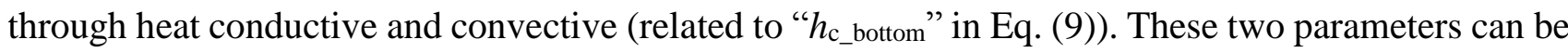
regulated by changing the vacuum degree of the space between the glass cover and the plate (i.e., the vacuum degree of the air gap) and adjusting the thermal conductivity of the backside thermal insulation, respectively. Fig. 12 illustrates the respective effect of $h_{\text {c_一 }_{-} \text {top }}$ and $h_{\text {c_bottom }_{-}}$on the cooling performance of the plate under normal and extreme conditions. The extreme condition means in which the $h_{\mathrm{c} \_ \text {top }}$ and $h_{\text {c_bottom }}$ are zero in the simulation. It is clear from Fig. 12 that the $h_{\text {c_top }}$ value shows a positive effect 
while the $h_{\mathrm{c} \_ \text {bottom }}$ exerts a negative one on the cooling performance of the PV/T module. Compared to the performance under the normal condition, the stagnation temperature of the plate is rather close $\left(22.94 \rightarrow 23.15^{\circ} \mathrm{C}\right)$ but the maximum cooling power of the plate is distinctly inferior $(35.87 \rightarrow 28.73$ $\mathrm{W} / \mathrm{m}^{2}$ ) when $h_{\mathrm{c} \_ \text {top }}=0$. In contrast, when $h_{\mathrm{c} \_ \text {bottom }}=0$ the maximum cooling power is the same as that in the normal case but the stagnation temperature of the plate is about $1{ }^{\circ} \mathrm{C}$ lower, from 22.94 to $21.85^{\circ} \mathrm{C}$. In general, both daytime solar heating and nighttime radiative cooling performance of the $\mathrm{PV} / \mathrm{T}$ module will benefit from decreasing the value of $h_{\mathrm{c} \_ \text {bottom. }}$. However, as the plate temperature is greater than the glass cover, the direction of net convective heat flux is from the plate to the cover, and thus reducing the $h_{\mathrm{c} \_ \text {top }}$ value will improve the diurnal solar thermal efficiency but downgrade the nocturnal cooling performance of the PV/T module.

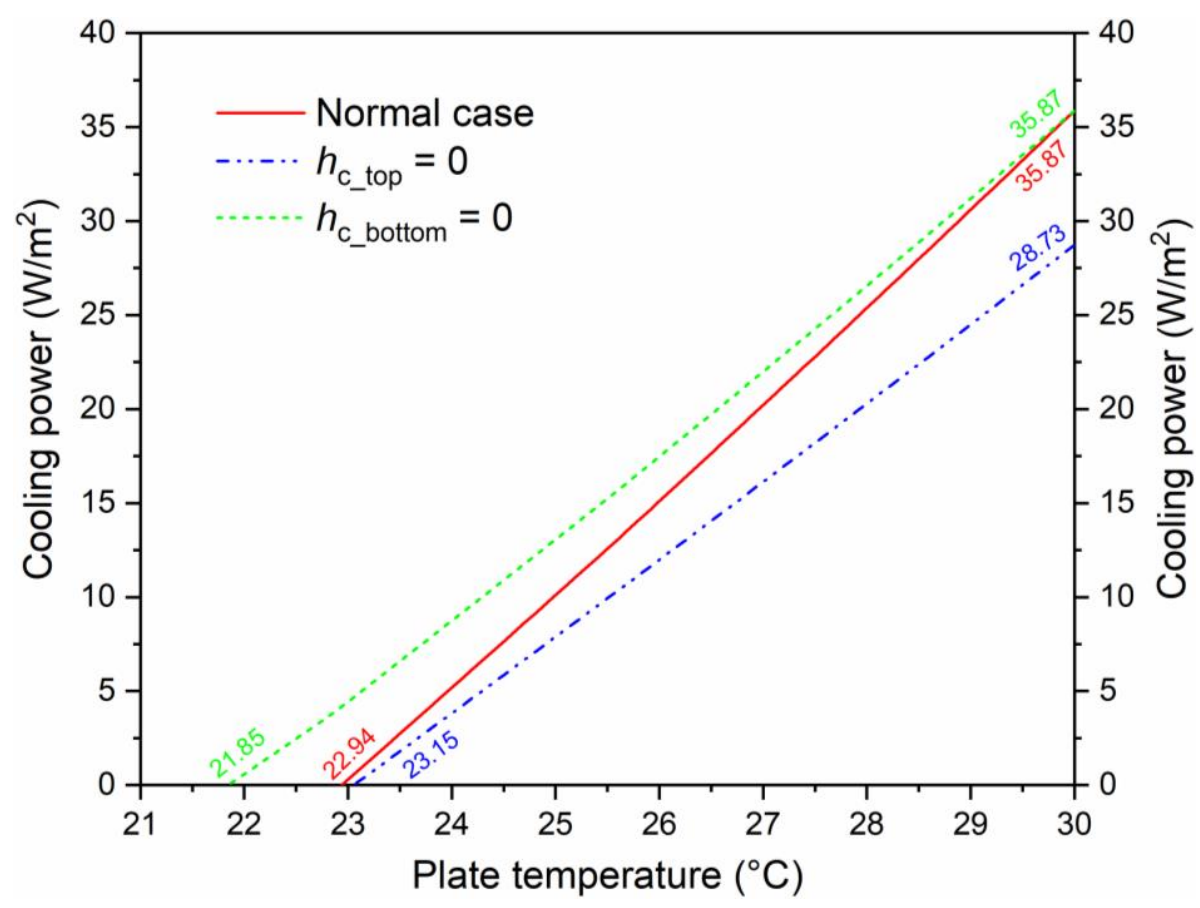

Fig. 12. The effect of the non-radiative heat coefficient on the cooling power of the plate. The ambient temperature and wind velocity are set at $30^{\circ} \mathrm{C}$ and $1 \mathrm{~m} / \mathrm{s}$, respectively.

\subsubsection{Wind velocity}

In typical radiative cooling modules, the plate is the radiator and the cover only serves as a wind- 
screen. Therefore, the cooling performance of the radiative cooling module is not very sensitive to the wind velocity. However, the glass cover of the present PV/T module, as the radiative cooling component, contacts with ambient air directly and thus its stagnation temperature may be dramatically influenced by the wind velocity. Fig. 13 shows the effect of wind velocity on the temperature of the glass cover and the cooling power of the plate. It is obvious that lower wind velocity corresponds to better cooling performance. When there is no wind (i.e., $u_{\mathrm{a}}=0 \mathrm{~m} / \mathrm{s}$ ), the maximum cooling power of the plate comes up to $43.14 \mathrm{~W} / \mathrm{m}^{2}$ and its stagnation temperature is recorded $20.17^{\circ} \mathrm{C}$. By contrast, as the wind velocity increases to $5 \mathrm{~m} / \mathrm{s}$, the two key performance indicators change sharply to $21.14 \mathrm{~W} / \mathrm{m}^{2}$ and $26.60{ }^{\circ} \mathrm{C}$. Besides, the difference in these indicators becomes larger as the wind velocity gets smaller. Moreover, Fig. 13 reveals that at the stagnation state, the temperature of the glass cover and plate is almost the same under any wind velocity (see the five orange dots in Fig. 13). For example, the stagnation temperature of the cover and plate are respectively 23.88 and $24.45{ }^{\circ} \mathrm{C}$ when the wind velocity is $2 \mathrm{~m} / \mathrm{s}$. In general, unlike the plate and cover emissivity, the wind velocity is basically an uncontrollable parameter and varies constantly in actual application scenarios and thus we can only place the $\mathrm{PV} / \mathrm{T}$ module in a circumstance where the wind velocity is low if better cooling performance is pursued. 


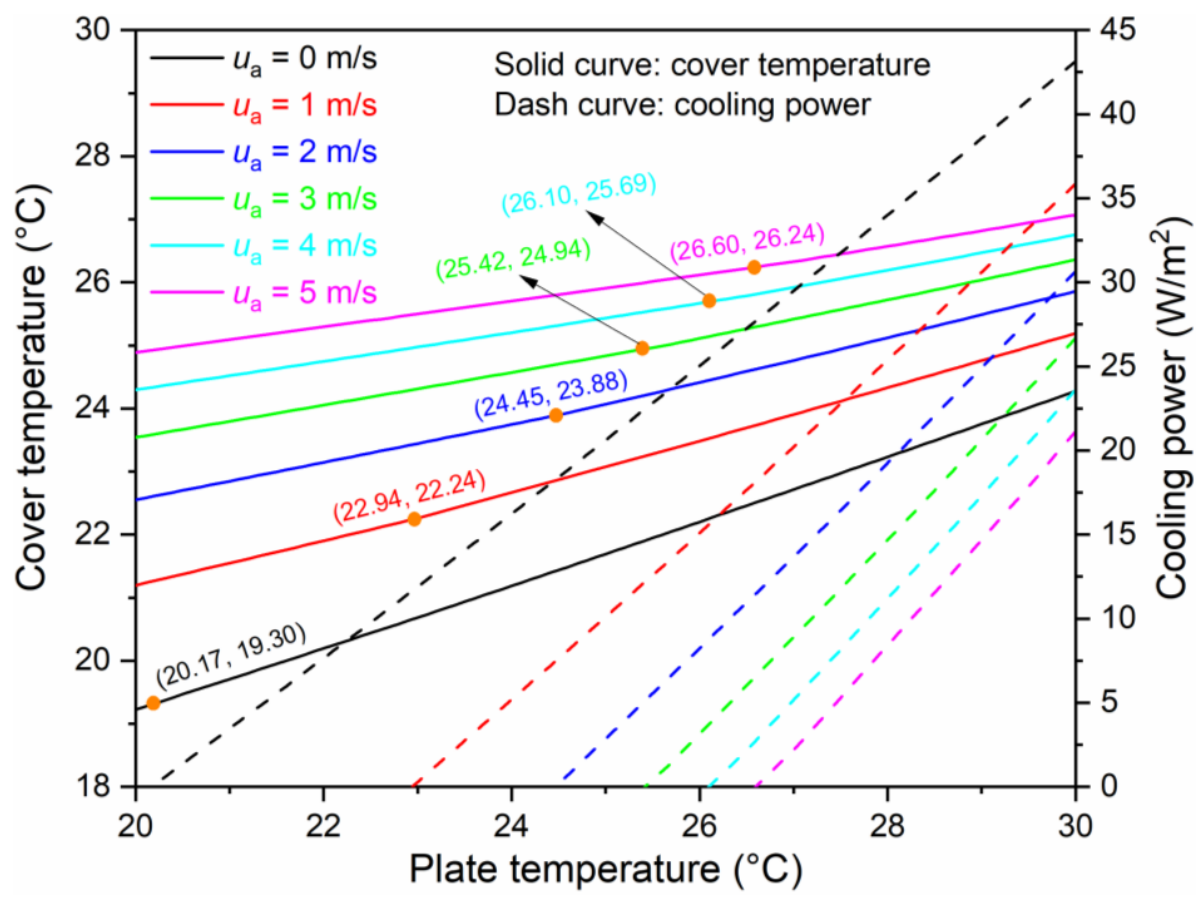

Fig. 13. The temperature of the glass cover and the cooling power of the plate under different wind velocities. The ambient temperature is set at $30^{\circ} \mathrm{C}$.

\subsubsection{Ambient temperature}

In addition to wind velocity, ambient air temperature is another environmental parameter that is uncontrollable but may have a great impact on the cooling performance of the PV/T module. As the cooling energy is basically required more in high-temperature weather, we set the ambient temperature varying from 25 to $40{ }^{\circ} \mathrm{C}$ in the simulation. Fig. 14 shows the effect of ambient temperature exerted on the cooling performance of the PV/T module. Higher ambient temperature signifies better cooling performance. The maximum cooling power of the plate is $32.98 \mathrm{~W} / \mathrm{m}^{2}$ when the ambient temperature is $25^{\circ} \mathrm{C}$, but the value increases to $42.06 \mathrm{~W} / \mathrm{m}^{2}$ as the ambient temperature goes up to $40{ }^{\circ} \mathrm{C}$. Moreover, the temperature gap between the plate at its stagnation state and the ambient air $\left(\Delta T_{\text {ap }}\right)$ gradually enlarges as the ambient temperature increases, but this enlargement is non-obvious. In specific, $\Delta T_{\text {ap }}$ is respectively $6.67,7.06,7.45$, and $7.84{ }^{\circ} \mathrm{C}$ when the ambient temperature is $25,30,35$, and $40{ }^{\circ} \mathrm{C}$, correspondingly. Mechanically, a higher ambient temperature pulls up the temperature of the glass 
cover and plate, and thus the plate radiatively dissipates more heat to the cover and so the cover to the cold sky, resulting in better cooling performance of the PV/T module.

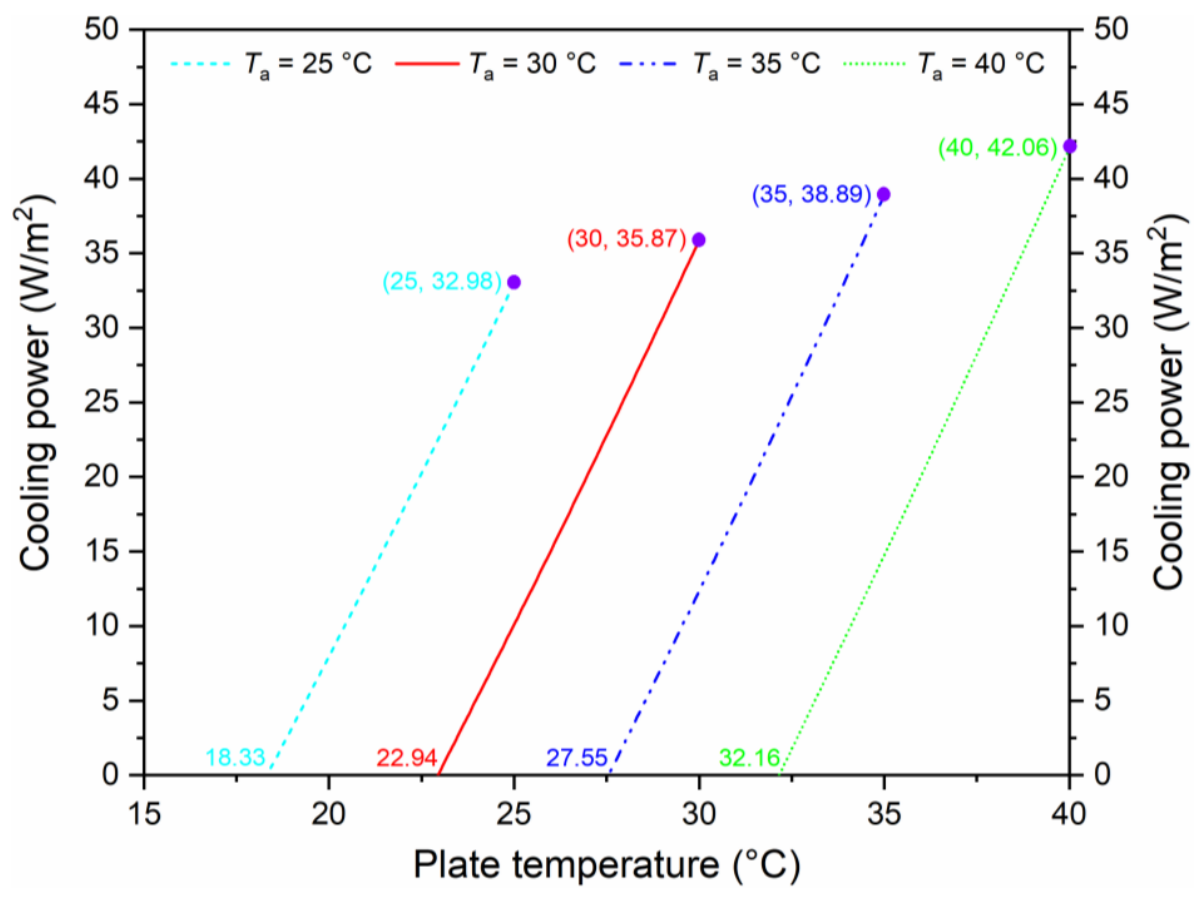

Fig. 14. The effect of ambient temperature on the cooling power of the plate. The wind velocity simulation is set at $1 \mathrm{~m} / \mathrm{s}$.

Since wind velocity and ambient temperature vary all the time simultaneously in actual scenarios, it is instructive to further evaluate the coupling effect of these two environmental parameters on the cooling performance of the PV/T module. Figs. 15 and 16 respectively illustrate the coupling effect of wind velocity and ambient temperature on the stagnation temperature and maximum cooling power of the plate. $\Delta T_{\text {ap }}$ peaks at $10.73{ }^{\circ} \mathrm{C}$ when the wind velocity is $0 \mathrm{~m} / \mathrm{s}$ and the ambient temperature is $40{ }^{\circ} \mathrm{C}$, but the value drops to only $3.17^{\circ} \mathrm{C}$ as the wind velocity increase to $5 \mathrm{~m} / \mathrm{s}$ and the ambient temperature decrease to $25^{\circ} \mathrm{C}$. Additionally, the maximum cooling power of the plate is respectively 50.01 and $19.18 \mathrm{~W} / \mathrm{m}^{2}$ under the two "edge conditions". Therefore, the nighttime cooling performance of the $\mathrm{PV} / \mathrm{T}$ module is highly related to environmental conditions. It has the potential of showing quite good cooling behavior in favorable weather conditions but may exhibit little cooling capacity in some harsh 
weather conditions.

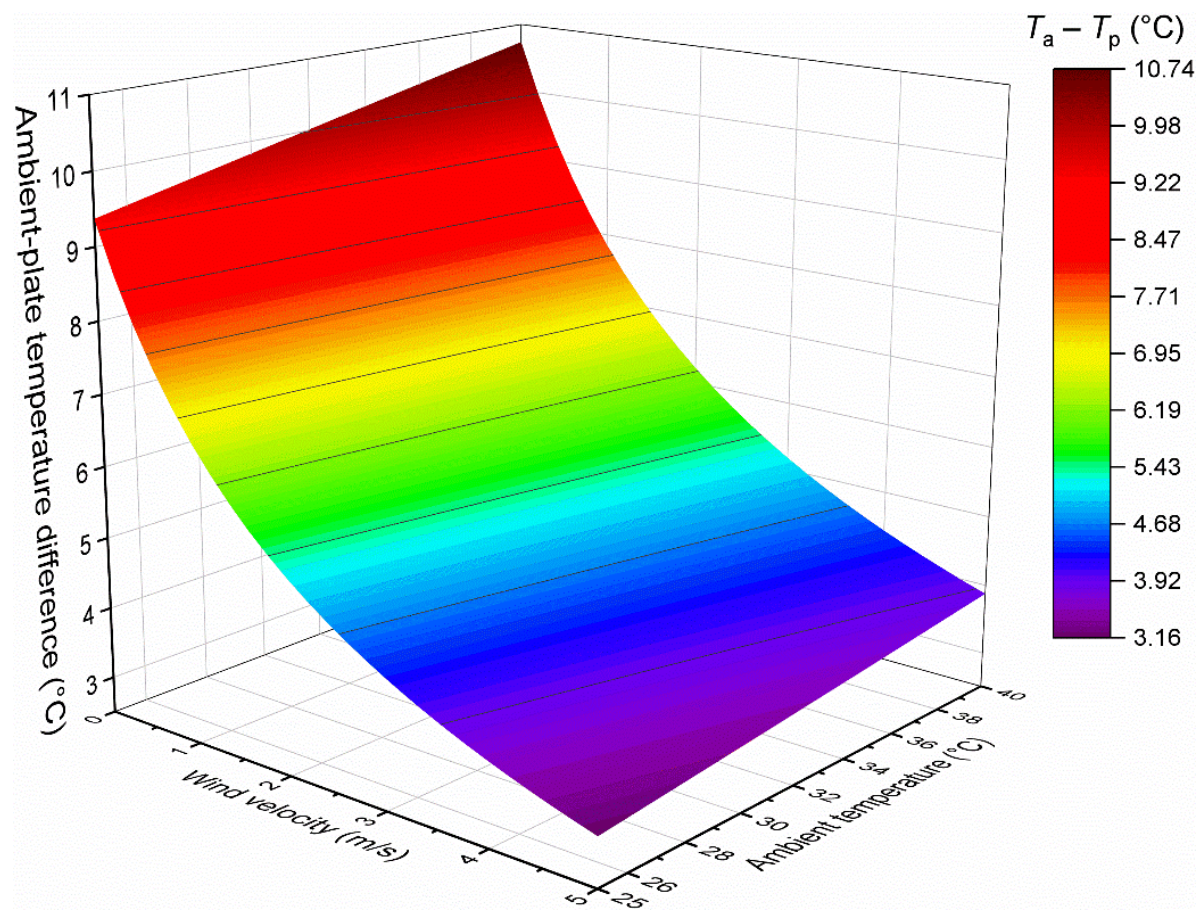

Fig. 15. The coupling effect of wind velocity and ambient temperature on the stagnation temperature of the plate.

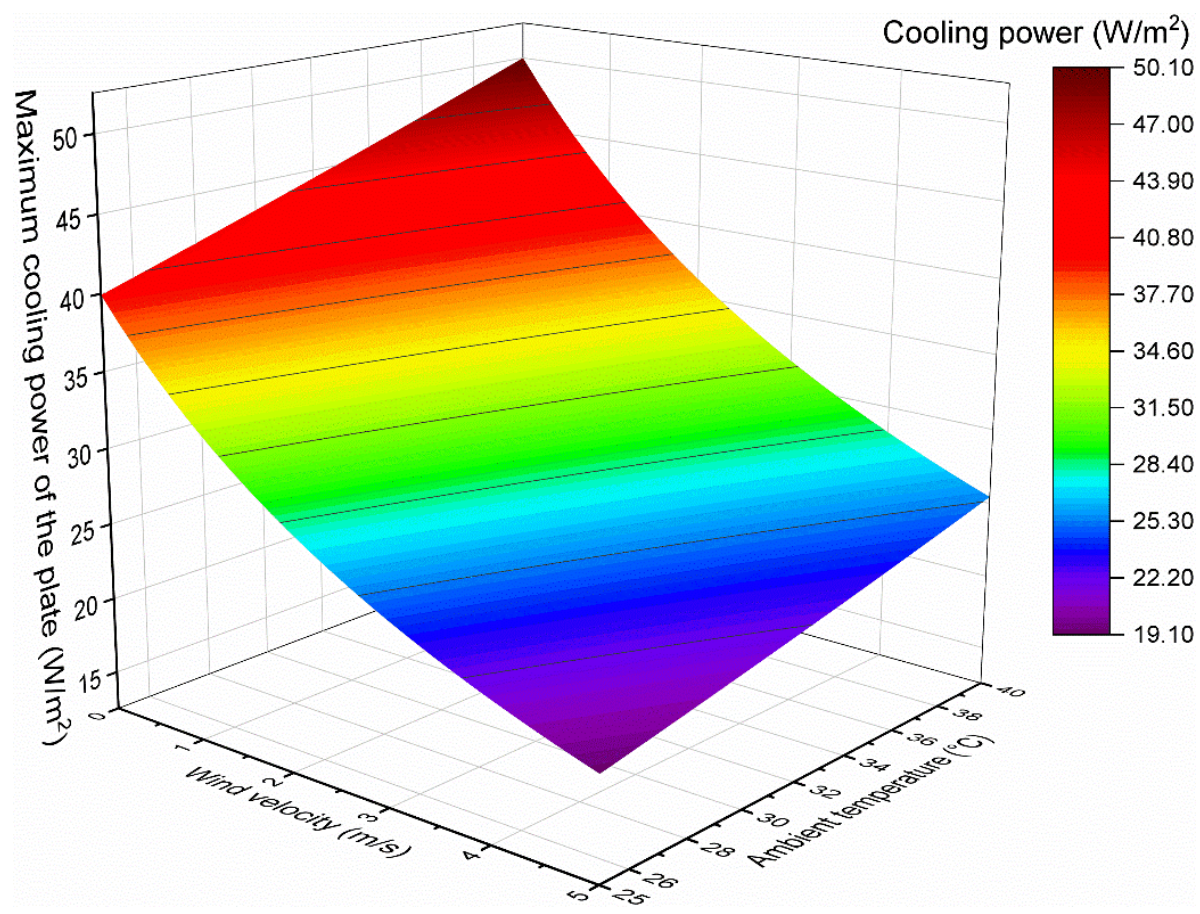

Fig. 16. The coupling effect of wind velocity and ambient temperature on the maximum cooling power of the plate.

\section{Conclusions}

In the present study, we demonstrated that without any modification in the structure, a flat-plate 
photovoltaic/thermal (PV/T) collector can still realize a noticeable radiative cooling feature, especially in some conditions which avail the effectiveness of radiative cooling. By developing a mathematic model for the nighttime performance characterization of a small-scale PV/T module, we conducted a thorough analysis regarding its potential in nighttime radiative sky cooling. The main findings are concluded as follows:

(1) Over a consecutive five hours nighttime period, the stagnation temperature of the glass cover and plate respectively cools to 10.32 and $9.42^{\circ} \mathrm{C}$ below the ambient temperature.

(2) As the plate already shows a long-wave emissivity, there is no need to further improve its emissivity by enhancing the radiative cooling performance of the PV/T module.

(3) Removing the emissivity dip of the glass cover near $10 \mu \mathrm{m}$ can improve the maximum cooling power of the plate by more than $10 \%$ and thus deserves to be developed in practical application.

(4) At a total water vapor columns (TWC) as low as $1000 \mathrm{~atm}-\mathrm{cm}$, the maximum cooling flux of the plate can reach over $40 \mathrm{~W} / \mathrm{m}^{2}$, which is comparable to that of typical radiative emitters.

(5) Reducing the convective heat transfer coefficient in the air gap suppresses the heat dissipation from the plate and thus deteriorates the radiative cooling performance of the PV/T module.

(6) The wind velocity exerts a remarkable influence on the cooling performance of the PV/T module. As the wind velocity increases from 0 to $5 \mathrm{~m} / \mathrm{s}$, the maximum cooling power and stagnation temperature of the plate change sharply from $43.13 \mathrm{~W} / \mathrm{m}^{2}$ and $20.17^{\circ} \mathrm{C}$ to 21.14 $\mathrm{W} / \mathrm{m}^{2}$ and $26.60^{\circ} \mathrm{C}$, correspondingly.

(7) Higher ambient temperature boosts the radiative cooling performance of the PV/T module. The maximum cooling power of the plate elevates from 32.98 to $42.06 \mathrm{~W} / \mathrm{m}^{2}$ as the ambient temperature increases from 25 to $40{ }^{\circ} \mathrm{C}$. 
In summary, although the radiative cooling performance of the glazing-covered PV/T collector is not as good as that of typical radiative coolers, it is still charming and attractive to use it as a nighttime radiative cooler in addition to being a daytime solar energy harvester. The PV/T collector, with the nighttime cooling potential being recognized, can be applied in fields such as buildings, agriculture, industry, and vehicles where electricity, heat, and cooling energy are all required. Take building energy saving as an example, by integrating the PV/T collector into the building envelop either alone or with an inherent Heating, Ventilation and Air Conditioning (HVAC) system, the collector can provide electricity throughout the year, deliver heat in cold seasons, and offer coldness in hot seasons with tiny pump power consumption. Future studies will focus on developing a full-scale PV/T collector/system and experimentally investigating its nighttime radiative cooling performance under outdoor operating conditions, as well as characterizing its annual/seasonal performance in different typical climate regions.

\section{Acknowledgments}

This study was sponsored by the National Key R\&D Program of China (2018YFD0700200), H2020 Marie Skłodowska-Curie Actions - Individual Fellowships (842096), National Natural Science Foundation of China (NSFC 51906241, 51761145109 and 51776193), Anhui Provincial Natural Science Foundation (1908085ME138), and China Postdoctoral Science Foundation (2019M652209).

\section{References}

[1] Zhao D, Aili A, Zhai Y, Xu S, Tan G, Yin X, et al. Radiative sky cooling: Fundamental principles, materials, and applications. Applied Physics Reviews. 2019;6(2).

[2] Liu J, Zhou Z, Zhang D, Jiao S, Zhang Y, Luo L, et al. Field investigation and performance evaluation of sub-ambient radiative cooling in low latitude seaside. Renewable Energy. 2020;155:90-9.

[3] Zhang K, Zhao D, Yin X, Yang R, Tan G. Energy saving and economic analysis of a new hybrid radiative cooling system for single-family houses in the USA. Applied Energy. 2018;224:371-81.

[4] Chen Z, Zhu L, Raman A, Fan S. Radiative cooling to deep sub-freezing temperatures through a 24-h day-night cycle. 
Nat Commun. 2016;7:13729.

[5] Zhao B, Hu M, Ao X, Pei G. Performance evaluation of daytime radiative cooling under different clear sky conditions. Applied Thermal Engineering. 2019;155:660-6.

[6] Raman AP, Anoma MA, Zhu L, Rephaeli E, Fan S. Passive radiative cooling below ambient air temperature under direct sunlight. Nature. 2014;515(7528):540-4.

[7] Yang Y, Long L, Meng S, Denisuk N, Chen G, Wang L, et al. Bulk material based selective infrared emitter for sub-ambient daytime radiative cooling. Solar Energy Materials and Solar Cells. 2020;211:110548.

[8] Dimoudi A, Androutsopoulos A. The cooling performance of a radiator based roof component. Solar Energy. 2006;80(8):1039-47.

[9] Bempah KO, Kwon K, Kim KA. Experimental study of photovoltaic panel mounting configurations for tube-shaped structures. Applied Energy. 2019;240:754-65.

[10] Karki S, Haapala KR, Fronk BM. Technical and economic feasibility of solar flat-plate collector thermal energy systems for small and medium manufacturers. Applied Energy. 2019;254:113649.

[11] Zhao B, Hu M, Ao X, Chen N, Pei G. Radiative cooling: A review of fundamentals, materials, applications, and prospects. Applied Energy. 2019;236:489-513.

[12] Zhao B, Hu M, Ao X, Pei G. Conceptual development of a building-integrated photovoltaic-radiative cooling system and preliminary performance analysis in Eastern China. Applied Energy. 2017;205:626-34.

[13] Zhao B, Hu M, Ao X, Chen N, Xuan Q, Jiao D, et al. Performance analysis of a hybrid system combining photovoltaic and nighttime radiative cooling. Applied Energy. 2019;252.

[14] Yong C, Yiping W, Li Z. Performance analysis on a building-integrated solar heating and cooling panel. Renewable Energy. 2015;74:627-32.

[15] Vall S, Castell A, Medrano M. Energy Savings Potential of a Novel Radiative Cooling and Solar Thermal Collection Concept in Buildings for Various World Climates. Energy Technology. 2018;6(11):2200-9.

[16] Eicker U, Dalibard A. Photovoltaic-thermal collectors for night radiative cooling of buildings. Solar Energy. 2011;85(7):1322-35.

[17] Liang R, Zhou C, Zhang J, Chen J, Riaz A. Characteristics analysis of the photovoltaic thermal heat pump system on refrigeration mode: An experimental investigation. Renewable Energy. 2020;146:2450-61.

[18] Zhu L, Raman A, Wang KX, Anoma MA, Fan S. Radiative cooling of solar cells. Optica. 2014;1(1).

[19] Matsuta M, Terada S, Ito H. Solar heating and radiative cooling using a solar collector-sky radiator with a spectrally selective surface. Solar Energy. 1987;39(3):183-6.

[20] Hu M, Pei G, Wang Q, Li J, Wang Y, Ji J. Field test and preliminary analysis of a combined diurnal solar heating and nocturnal radiative cooling system. Applied Energy. 2016;179:899-908.

[21] Mandal J, Jia M, Overvig A, Fu Y, Che E, Yu N, et al. Porous Polymers with Switchable Optical Transmittance for Optical and Thermal Regulation. Joule. 2019;3(12):3088-99.

[22] Chen Z, Zhu L, Li W, Fan S. Simultaneously and Synergistically Harvest Energy from the Sun and Outer Space. Joule. 2019;3(1):101-10.

[23] Zhou J, Zhao X, Yuan Y, Li J, Yu M, Fan Y. Operational performance of a novel heat pump coupled with mini-channel PV/T and thermal panel in low solar radiation. Energy and Built Environment. 2020;1(1):50-9.

[24] Hu M, Zhao B, Ao X, Ren X, Cao J, Wang Q, et al. Performance assessment of a trifunctional system integrating solar PV, solar thermal, and radiative sky cooling. Applied Energy. 2020;260.

[25] Lin W, Ma Z, Sohel MI, Cooper P. Development and evaluation of a ceiling ventilation system enhanced by solar photovoltaic thermal collectors and phase change materials. Energy Conversion and Management. 2014;88:218-30.

[26] Hu M, Zhao B, Ao X, Zhao P, Su Y, Pei G. Field investigation of a hybrid photovoltaic-photothermic-radiative cooling system. Applied Energy. 2018;231:288-300. 
[27] Al-Waeli AHA, Sopian K, Chaichan MT, Kazem HA, Hasan HA, Al-Shamani AN. An experimental investigation of SiC nanofluid as a base-fluid for a photovoltaic thermal PV/T system. Energy Conversion and Management. 2017;142:547-58. [28] Hu M, Zhao B, Ao X, Su Y, Wang Y, Pei G. Comparative analysis of different surfaces for integrated solar heating and radiative cooling: A numerical study. Energy. 2018;155:360-9.

[29] Zhai Y, Ma Y, David SN, Zhao D, Lou R, Tan G, et al. Scalable-manufactured randomized glass-polymer hybrid metamaterial for daytime radiative cooling. Science. 2017;355(6329):1062-6.

[30] Long L, Yang Y, Wang L. Simultaneously enhanced solar absorption and radiative cooling with thin silica micro-grating coatings for silicon solar cells. Solar Energy Materials and Solar Cells. 2019;197:19-24.

[31] Li W, Shi Y, Chen K, Zhu L, Fan S. A Comprehensive Photonic Approach for Solar Cell Cooling. ACS Photonics. 2017;4(4):774-82.

[32] Gang P, Huide F, Tao Z, Jie J. A numerical and experimental study on a heat pipe PV/T system. Solar Energy. 2011;85(5):911-21.

[33] Guo C, Ji J, Sun W, Ma J, He W, Wang Y. Numerical simulation and experimental validation of tri-functional photovoltaic/thermal solar collector. Energy. 2015;87:470-80.

[34] Zhao B, Li X, Hu M, Ao X, Xuan Q, Pei G. Consideration of cooling loss process of the emitter for radiative cooling. Journal of Renewable and Sustainable Energy. 2020;12(1).

[35] Allouhi A, Benzakour Amine M, Buker MS, Kousksou T, Jamil A. Forced-circulation solar water heating system using heat pipe-flat plate collectors: Energy and exergy analysis. Energy. 2019;180:429-43.

[36] Hu M, Zhao B, Ao X, Chen N, Cao J, Wang Q, et al. Feasibility research on a double-covered hybrid photo-thermal and radiative sky cooling module. Solar Energy. 2020;197:332-43.

[37] http://climatemodels.uchicago.edu/modtran/. 